\title{
Design as a Critical Research
}

\section{Calejo, Marta ${ }^{a} \&$ Magalhães, Graça ${ }^{b}$}

âPhd Student, Fine Arts School, University of Porto, Portugal, martaluisacalejo@gmail.com.

b Assistant Prof. (PhD), Communication and Art Department, University of Aveiro, Portugal, gracamag@ua.pt.

\begin{abstract}
Historically the imaginary and the hegemonic thinking, in the Western globe north, has been marked by the epistemology and capitalists archetypes. Notwithstanding the design seem as a practice and discipline shielded on a simplistic discourse of functional / communicative efficiency, wandering through by multiple aestheticism apparently neutral in relation to the symbolic, but in fact they never are, because what really hapens is that the aesthetic appearance of the generated forms will always be a review of the powers ruling. We start from the understanding that the act of creating an aesthetic artifact, will also be a movement of inscription in a discursive platform (that precedes it), is in itself an narrative act and that fact represent a certain take place in relation to certain symbolic reality. On reflection shown if it sees design as a discipline and / or an instrument of action, whose operational relevance tends to question and simultaneously rehearsing a response, in which more than why interests answer to why.

Apparently the design is a content mediator, but also, it is structure, is body, is idea. We think a design praxis as discipline and enrollment tool of critical thought and social transformation. For guiding research in this text, we propose the following question: Can the Design want for themselves an engagement with the symbolic in order to be an active part in the production of critical thinking in the place where it belongs? Methodologically our argument will be present in two differents moments: 1. a first, exploratory nature where we rescue the draw issues in the practice of design and 2. a second analytical nature concerning the subject issues (graphic and / or utility) design and how it incorporates formal rites, political events and social practices of contemporary everyday life.
\end{abstract}

We consider the praxis of design as a discipline and critical thinking enrollment tool as agents of social transformation. With this study we seek for contribute phenomenology design by studying the artifacts of configuration as well as the possible messages they convey and what impact they may have on the social network.

Keywords: Politic, Transformation, Periphery, Project, Democracy 


\section{Introduction}

Historically the imaginary and the hegemonic thinking, in the Western globe north, has been marked by the epistemology and capitalists archetypes. Notwithstanding the design seem as a practice and discipline shielded on a simplistic discourse of functional / communicative efficiency, wandering through by multiple aestheticism apparently neutral in relation to the symbolic, but in fact they never are, because what really hapens is that the aesthetic appearance of the generated forms will always be a review of the powers ruling. We start from the understanding that the act of creating an aesthetic artifact, will also be a movement of inscription in a discursive platform (that precedes it), is in itself an narrative act and that fact represent a certain take place in relation to certain symbolic reality. On reflection shown if it sees design as a discipline and / or an instrument of action, whose operational relevance tends to question and simultaneously rehearsing a response, in which more than why interests answer to why.

Apparently the design is a content mediator, but also, it is structure, is body, is idea. We think a design praxis as discipline and enrollment tool of critical thought and social transformation. For guiding research in this text, we propose the following question: Can the Design want for themselves an engagement with the symbolic in order to be an active part in the production of critical thinking in the place where it belongs? Methodologically our argument will be present in two differents moments: 1. a first, exploratory nature where we rescue the draw issues in the practice of design and 2. a second analytical nature concerning the subject issues (graphic and / or utility ) design and how it incorporates formal rites, political events and social practices of contemporary everyday life.

We consider the praxis of design as a discipline and critical thinking enrollment tool as agents of social transformation. With this study we seek for contribute phenomenology design by studying the artifacts of configuration as well as the possible messages they convey and what impact they may have on the social network.

\section{Of Drawing}

We will start with considering two exploratory projects in drawings, which start from a common base, which consists of thinking design as a catalyst for improvise, for error and for the imponderable. With these projects, it was intended to think and reflect drawing as a cartographer for the performative gesture of the quotidian, and the devices of drawing are a prosthetic artefact that is simultaneously a mediator and translator of the conversion of movement (of a body in a space) in design/image production. Drawings characterized by a certain unpredictability, a certain wandering, a certain narrative and meta-narrative chaos. We can legitimately understand these drawings as the narrative sense's linear economy, configuring itself mainly as pure management of randomness, where design is the transgression of the norms that constrain the inhabitability of spaces, constructing/reconstructing this shift, normalizing the unpredictable. As we will be able to verify, these are a set of drawings that close among themselves, without a remote control, where it is virtually impossible to predict a beginning, impossible to define an order of action through tem or through contemplating them.

\subsection{As a cartographer of the gesture of the body in a quotidian space}

The first drawing experience was drafted in 2004, and only years later (2013) was it resumed, inserted within a lecture on drawing (Drawing in the University Today). As this early stage, the methodical processes of creation in drawing were composed of a daily log (throughout precisely 18 days) of the movements produced in a household, by the people who cohabited the space, as well as by the objects belonging to it. In a living space as well as in cities, there are passage spaces, where people pass by but 
don't stop (like hallways), others where one fixates for a longer period of time, and also dead spaces, where nothing happens (like the spaces under furnitures). In order for such $\log / \mathrm{mapping}$ to occur (of the movements of body and objects), it was required to cover the entire floor of the household with scenery paper, converting the simple living experience of body in a space in an engine of production of registry and consequently of drawing, through drawing devices, or recording prosthetics, the simple experience of a body in space was converted into record production of engine and consequently drawing. In that sense, the person who would enter the household space would be given "the logging machine". Their sole requirement was to inhabit the household space in a natural relationship with the spaces and objects belonging to it. We can state that we are facing the blueprint of a household at the 1x1 scale.
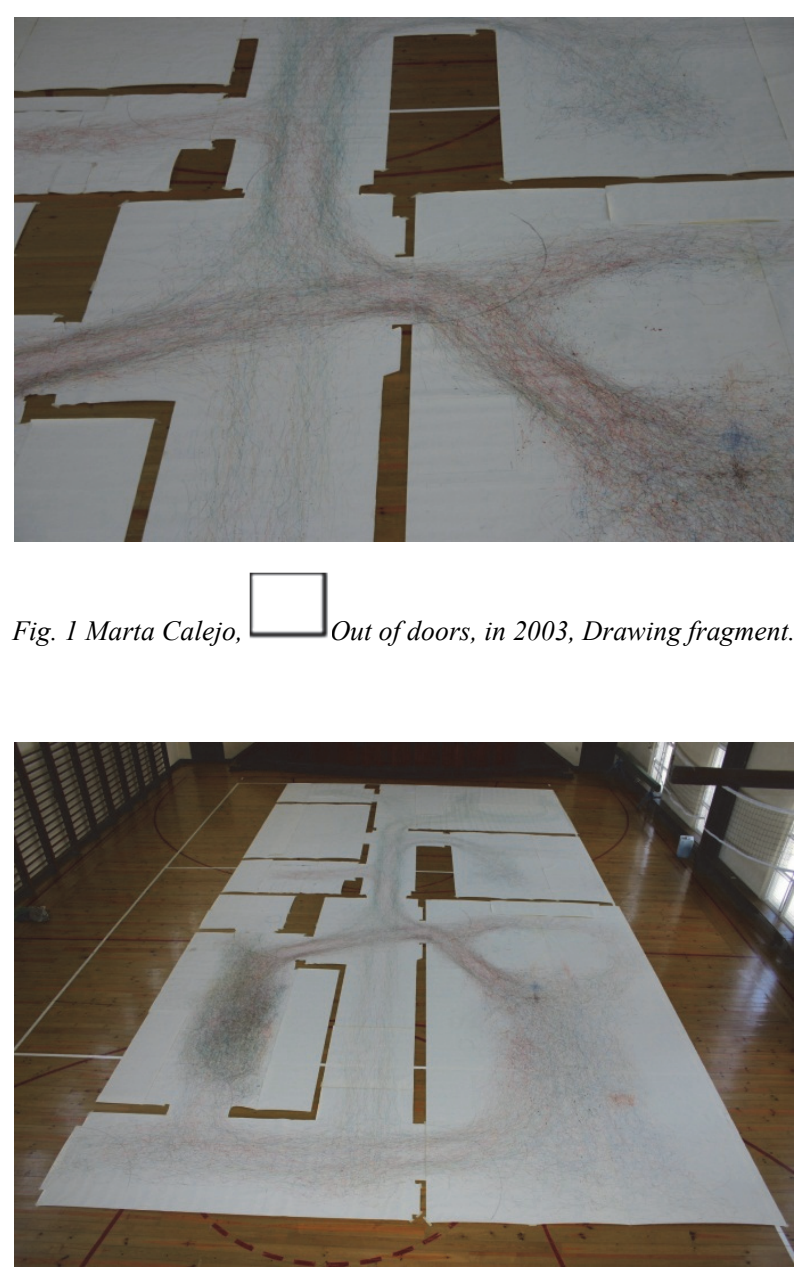

Fig. 2 Marta Calejo, Out of doors, in 2003, Drawing total view

Through this record, we can understand which are the most utilized spaces, as well as the established relationship between people and objects. We can state it is a quotidian hyper-narrative. A drawing intended to think of trace, marks, the unexpected and the error as a narrative constructing tacit force. Objects and bodies that intersect, that leave marks and mutually draw each other, in a coexistence that is not peaceful because it is, in certain moments, unpredictable. Unpredictability gains, in this context, a new meaning, translated by the coexistence of space, which are gesture, movement and drawing. We perceive drawing here as a direct and automatic projection of life (whose conceptual proximity was 
inspired in Pollock). This modus of the drawing is marked by an accumulation of lines that, by saturation, prevent a unequivocal reading of events. In this experience, there are, occasionally, little text notes that work as small subtitles, which describe and/or denounce some movements that have existed but are no longer there, and not through the gesture/movement translation that may have left a trace/mark.

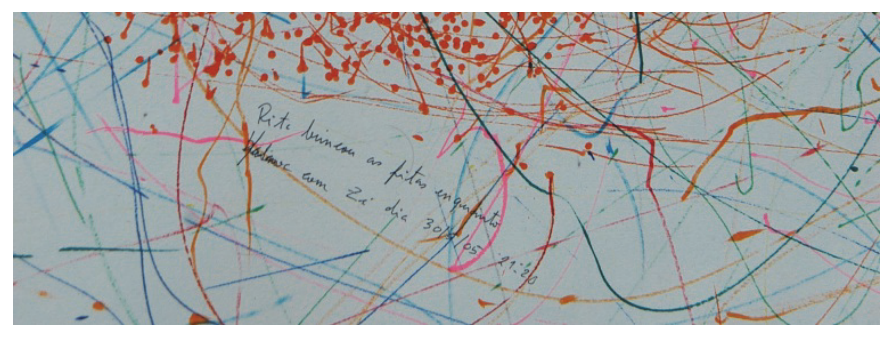

Fig. 3 Drawing detail with legend. Author (2003)

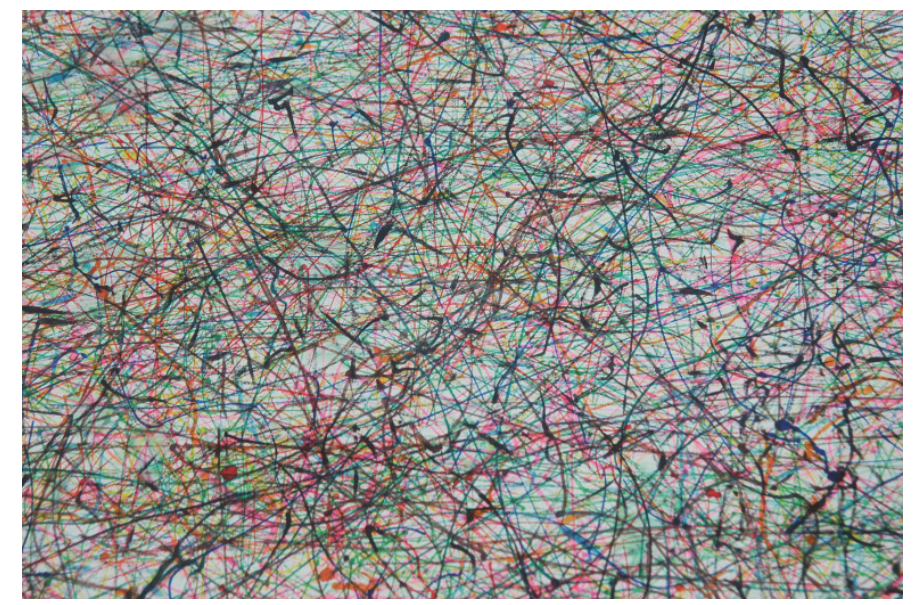

Fig. 4 Drawing mesh detail. Author (2003)

Therefore, spaces are defined as well by the type of registry that they make; i.e., the types of marks that appear in situs define spaces and the kind of coexistences and actions that embody the place. When we think of actions, we report to two levels of existence, construction and reconstruction, simultaneously. Those that are calculated (I'm going this way, in which there is the consciousness that one is producing a drawing), and the unpredicted ones (accidentally, one drops a cup of coffee, adding unpredicted information to the drawing). The accident as a pivotal characteristic of the construction and thought process of drawing. This drawing modus transfers to paper the natural processes. The gestures of the body and what they produce in their relation with real space are of a tri-dimensional realm. For example, when a cup falls, it produces a movement in the tri-dimensional space, but when the ending of the fall occurs, a bi-dimensional mark is inevitably printed, that is a trace of what occurred, it is a mirage of a supposed event. We can state it is a certain "thickness" of the image, because it materializes in a gesture making it bi-dimensional, leaving its tri-dimensional nature as an "embedded" reality, a reality "beyond", a reality that it supposed to have occurred, but of which only its results are known, meaning, the marks that compose it. We will go as far as to claim that they are perhaps the consequent result of the sums of accidental ready made, and not a choice - they occur in an unpredictable fashion, without given time or 
space. Echo's of memory, that transfers to the drawing a narrative and meta-narrative map of a quotidian existence in a real space (house) and of space as a container of residues/ marks/ traces (drawing).

\subsection{As a cartographer for gesture in the absence of an event}

In this second experiment, like in the previous one, we start off from an interpretation of drawing as a cartographer for experiences occurred in a determinate space. But, whereas in the previous drawing the entire floor of a house was covered in paper along a period of 18 days, in this project we contained the action space in a single compartment of the household through a period of 6 hours. In this experience, twenty adults and two children were present (the children were not initially planned for the project). The registers of the children's bodies are differentiated, as it is expected that the manner in which the children manage their coexistence in the space, and of their bodies will be necessarily different. If in the previous project the mesh of traces was colourful, here the option was to create a code of colours that allowed that perceptive differentiation in the graphic log to exist in a clear and indubitable way - to that effect, the following was defined: black markers for adults and red markers for children - like in a map, where paths of differentiated natures have differentiated registers. The results demonstrate that children had not only a different relationship with space, but also a different relationship with the materiality of the drawing, producing a record that not only translated their movements in a graphic image, but also required in certain moments the manipulation of the markers.

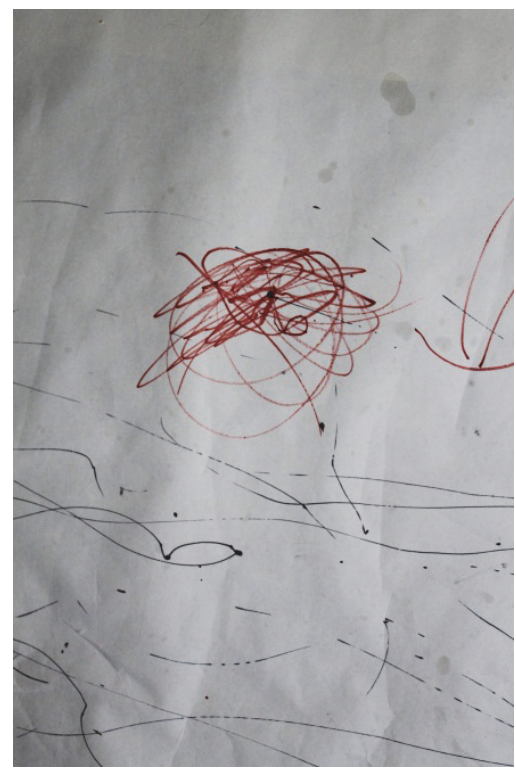

Fig. 5 Traces generated by child. Author (2014)

Peggy Phelan, about performance art, said 'the performance enters the economy of reproduction, it diminishes the promise of its own ontology (...) the ethos of the performance, like in the proposed ontology of subjectivity, is reached by way of disappearance (Phelan, 1993: 171).' In this process, drawing is also created through disappearance, for of the event per si, or what emerges from it, is the record as trace of action. This is, therefore, a drawing that stumbles in the gestures of an action. In the drawing or the drawing modus here represented, it is looked upon as something that is documented, collecting in a single space of consignment an account of marks and evidences of a determined event, and in this concrete case, like Jacques Le Geoff taught us, this drawing is simultaneously a document and a 
monument of the event (Paul Ricoeur 1978: 68). However, this sum of gestures converted in traces is not linear not peaceful, for with any addition of record (trace) a subtraction to the previous information is perceived, through the overlap of a new record. In the same manner as the previous experience, here the drawing also documents the movements of the body in a space, and this was made possible because 'drawing prostheses', similar to the previous ones, were indexed to the bodies of the inhabitants or coinhabitants of the space, where the paper covered floor served as a support for the drawing.

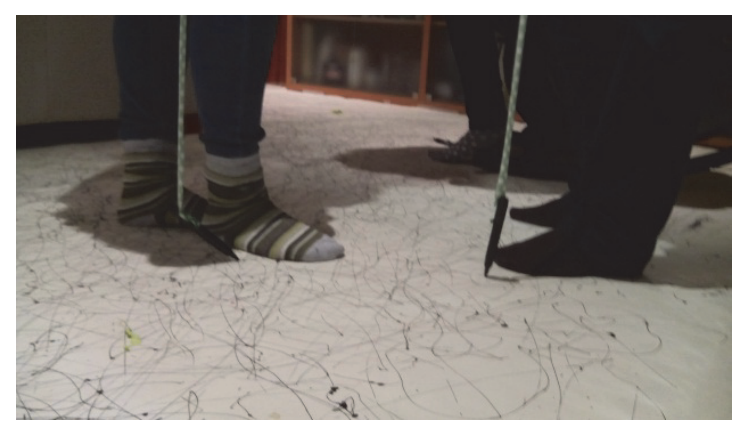

Fig. 6 Drawing prostheses' in use. Author (2014)

Methodologically, within this creative process, drawing is seen as a document, a testimonial of an event, i.e., as proof/evidence (although a speculative one) that something occurred there, and in that sense, we can state that the generated artefact assumes, tacitly, the shape of a spectrum or a mirage of an action. Lets resume, from the theories of Derrida (1997), the concept of spectre in order to expose a drawing with an appearance that subverts positions between reality and fiction. In this instance we assume spectre as something that is imagined to have happened and, in that sense, drawing is read as a stimulus of an event, i.e., an incentive (although a speculative one) to memory so that something that will soon be absent becomes present. There are similarities the work of Sophie Calle, Ghosts, presented in the Dislocation exposition, at the Museum of Modern Art (MOMA), in New York, in 1991, where she exposes what the museum does not have and what the museum cannot offer, using that absence to create her work. Similarly, this is a drawing forged in the absence of an event.

Therefore, in this second experience, the drawing is a fruit of an event, that was intended as consequence of a drawing that sub-exists, suggesting that its energy is generated in the absence of an event. Thus, if in the described project, in point 2.1, short notes were taken along the drawing that recorded the events and the objects that composed the everyday existence in a space (in a taxonomical record of actions), in this second project such references and orientation notes for the reading of the drawing (and of the events occurred in a space) were not made, precisely because the intent was to think of drawing as speculation that generates in the absence of the event, for what we keep from it is a trace, and not the action itself.

From what was described, we can state that we are facing a number of drawings, which their mimesis of trace becomes impracticable, it resists, like in performance art, to reproducibility (Phelan, 1993: 171173). This impossibility (of mimicry) is one of the prepositions that we are interested in exploring in the processes of projecting and thinking in design. It is easily verified in some of the objects that we selected for this investigation (fig. 7 and 8) the impracticability of mimicking these objects, outside of their social and political context. 


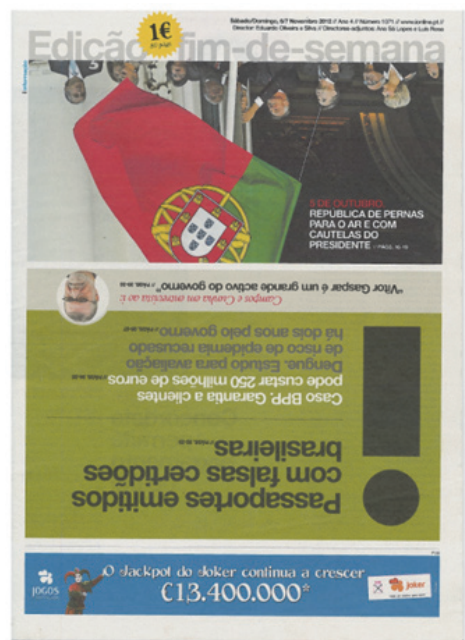

Fig. 7 Jornal i, First page of the Jornal I, 6-7 October 2012.

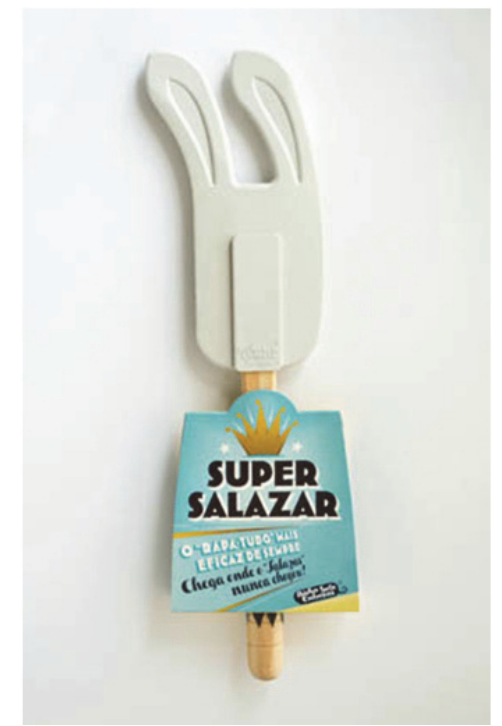

Fig. 8 Super Salazar. POPs - Original Portuguese Project. Martins (2013)

Such objects are indexed to specific events and places. For that reason, these are objects that in other places and contexts would result in loss of discursive and symbolic sense. We suggest that apparently such characteristic gives evidence to the artistic heritage of Design.

\section{Of Design}

In its origin, Design would be the natural heir to the discipline of Drawing. Perhaps, due to its disciplinary proximity, Design, as a creative practice, rescues the above mentioned marks, incorporating itself in a depurated manner (Fig. 9 and 10) ) $^{54}$ in the formal assumption of the object of Design and with that it

${ }^{54}$ The objects we present in this article appear as examples, merely illustrative of what we propose as a desirable conduct for a conception of design which sees it with bigger ethical, social and political implications. 
rescues a creation process, that is in its genesis, an heir to drawing practices, and adds diverse levels of significance that we propose to explore.

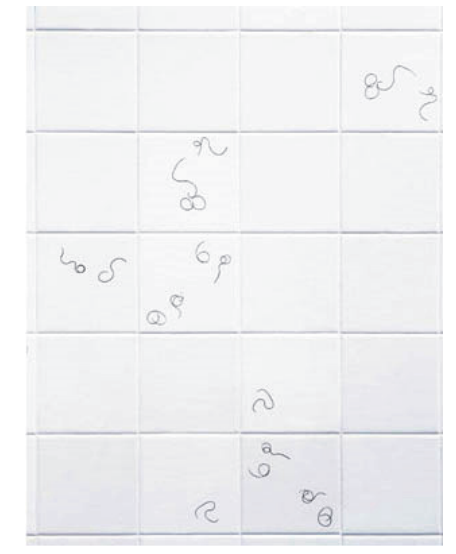

Fig. 9 Hair disguiser. Ceramics, decorative tiles for toilet. Mir (1994-1999)

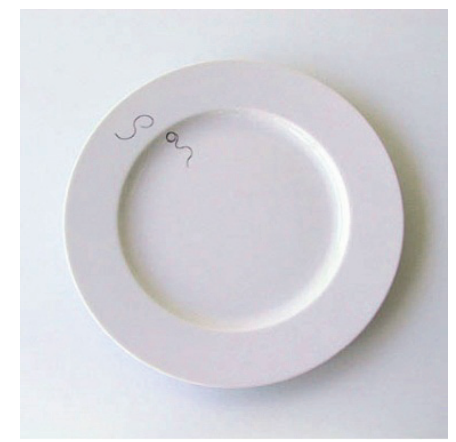

Fig. 10 Hair Disguiser Series, Dish. Ceramic. Mir (2003)

Starting from the shape-function equation, there are objects in which their shape emancipates from their function, thus representing a liberation of the object, adding other levels of significance to it. For our investigation, we have elected a set of objects that, although coming from a mass production and of utility purposes, are potentially capable of assuming narratives that go beyond their function. They are limit objects that put to evidence vestige of a narrative or an event that transcends its dimension of utility object. In light of Michell Foucault's heterotopia notion, we consider that we are facing fragment-objects capable of incorporating realities that go beyond their bodily boundaries and, this way, present themselves as operative elements that manage to free themselves (through their intrinsic characteristics) from their condition of a mere utility object. These objects are conceptually capable of anticipating formulations and relating conceptual data that stand far beyond the object itself and the technological aspect that composes them, transferring in this manner the natural function that they were destined to initially.

This way, we can state that: the objects we have been enunciating are artefacts capable of positioning conceptually and/or politically before phenomena that occur within the social context of its genesis. In that sense, we can state that such objects, of quotidian usage, emerge in the industrial production panorama, like elements of subversion. Object where one can apprehend a certain preoccupation in the production of critical through their own usability and/or functionalities of the artefact. We consider that 
these objects work as discursive 'empowerment', for they star and give voice to an alternative narrative to the hegemonic narrative. These are objects that communicate beyond their utility, i.e., beyond the canonical 'shape-function' formula. As objects of study, we are interested in the production in Design that understands the artefacts it creates as conceptual positioners by a determined symbolic context, i.e., Design as a shaper of consciousness, as an instrument of analysis and interaction with the Other.

We think of Design as a discursive tool while corpus of action. We see Design as a possibility of Democracy. In light of what we have been exposing, any of Ana Mir's or Madalena Martins' work are clear illustrations of that, for they largely surpass the shape-function dichotomy, to grant them levels of significance that transcend objects of a functional nature. The same occurs in the Jornal I newspaper's first page, as the rules of legibility of the newspaper's page were questioned according to structures of thought and creation processes that propose a critical positioning before specific events. Apparently, we are stand before objects of a quotidian utility, embedded with a subversive nature and questioning, through their own objectual interface, the rites, practices and/or socio-political events of the quotidian life. We believe that such synergy can be a motor for social transformation and production of critical thought in the social tissue in which it inserts. Like, Francisco Laranjo points out, "To be knowledgeable of the history of formal languages is an invaluable requisite in a practice that must always be contextualized (...)" (P3, 19/04/2016), in a profession which its ubiquitous work surrounds people's lives constantly and daily.

Jean Baudrillard (1968), in his theoretical legacy, reflected on the relations that objects establish with space, as well as its users, what type of experiences and judgements they make on the users that use them. Coming to the conclusion that multi-usage objects, capable of folding, in the way they relate with space and its users, manage to liberate from their function, but not exactly as an object.

'While the relationship of the individual in family and society changes, the style of objects and furniture changes as well. (...) In terms of the serial object, in the absence of space restructuring, this 'functional' evolution is simply to resume the Marxist distinction, an emancipation, not a liberation, since it only means the liberation of the object's function and not the object itself' (Baudrillard, 1968: 23-24)

In light of this formulation, we can state that the objects brought to analysis, although not fitting in the formal category of "multi-usage objects ${ }^{, 55}$, can be said to be objects that emancipate from their function and that, to a certain extent, free themselves from their object condition, through their formal characteristics as well as through the symbolic understanding we have of them. Clear examples of this are the objects presented in figures 8 and 7. They are objects, engaged with their users, with their time and place. This compromise apparently allows a liberation of the object (as a thing), and J. Baudrillard reclaimed its absence for objects of study.

In the present investigation, Design is approached as a discipline and/or action instrument, and its operative pertinence tends to problematize and simultaneously attempt an answer, in which, more than the why, it is important to answer to the what for? Apparently, Design is a mediator of contents, but is is also shape, it is structure, body, idea. We perceive Design as an element of transformation. Like J. Butler, regarding the semantic structure that predicts the performative act of the quotidian, that despite not being a direct event, it is first and foremost, the result of the repetition of strongly coded gestures that when appropriated incorrectly, provoke changes in the code of the symbolic and semiotic fabric that supports them. Or, like M. Foucault, whose theorization analysed the way things are shaped will always be a digest of the dominant powers. Or even, like Walter Benjamin when he studied the existence of a collective memory, considered to be the common semantic structure that rules us as elements that belong to the

\footnotetext{
${ }^{55}$ In his work, J. Baudrillard gives the sofa bed as an example.
} 
same nucleus. We think of Design as a tool with real possibilities of deconstructing the hegemonic narrative.

Just like Derrida, deconstruction or de-construction perceived as a double gesture that inverts the order and dislocates structure, i.e., by dislocating that structure we subvert the hegemonic order, provoking a structural alteration in the inside of it, and through that double movement a new order transforms and reinvents in the bosom of the society where the phenomenon occurs. Such subversion and reinvention of the order occurs when, through processes of differentiation, we alter a certain symbolic legacy. This process of re-presenting ${ }^{56}$, brought to the territory of Design, becomes a powerful instrument of the transformation of the hegemonic narrative. In other words, if we think of Design as a language, when we appropriate the symbols and pervert their semantic code, on a first instance, the consequence will be: the strangeness by the observer who, for the first time, looks at the transformed object. This strangeness is the disquieting pulse of the text (objected here), with its subtexts, that can legitimately be energizing elements of consciousness, a leitmotiv for the critical reflection of those (the user) that with it (the object) interact. The message or narrative meaning of the object crosses the sign (artefact of Design) reaching existence and significance outside of it (i.e., in the social fabric). The objects brought to investigation are semiotic elements that have multiple existences, and are everything but mono linguistic or a discursive bricabac. They represent an incentive to users' critical thought, to a permanent questioning of what happens around them.

This way, we perceive design as simultaneously an exercise of democracy and an instrument of production of critical thought. Assigning designers the double function of creators and critical agents. We debate for a Design with a possibility of creation that results from the possibility of the nature of the drawing manifesting itself in the object of quotidian usage, through creative and reflexive duality. Understanding the practice of Design as an instrument of creation encompassed by technical reproducibility, and being legitimately seen as an element of social transformation.

José Bártolo (2012), in his Manifest for the Portuguese Design, attempts to make room for the discussion of the demands of Design as a professional practice. Demanding a larger politicization of creative agents and a positioning on their part in the contents they create. Bártolo refers to Design 'as a form of social production and not as an isolated case of creativity ${ }^{57}$ and of its agents as social actors with ethical and political responsibilities in the contents they create.

\section{Final Considerations}

We understand the act of creation is also a movement of inscription in a discursive platform, continuing or not, an already existing narrative and, with this, a positioning before a determinate symbolic reality. In this sense, we interpret Design as a discursive tool, as a corpus of action, analysis and interaction with the Other. We are interested in the object and the processes of creation, as conceptual positioner, according to a determinate symbolic and discursive structure. We therefore speak of a Design that uses semiotics and its ubiquitous nature (for it is present in city life as much as in people's spaces) as a way of social, ethical and political compromise. Hence Design, as a creation tool, can be an element of social transformation. We believe that the eventually more critical nature of the object, seen as an operative symbolic element

\footnotetext{
${ }^{56}$ Linguistic game resumed from Derrida's essay, La Voix et le Phenomene, i.e., in the sense of a representative element replacing, occupying the place of another Vorstllung (Reprasentation) [Derrida 1967: 62]

${ }^{57}$ Excerpt taken from point 8 of the manifest Manifest for the Portuguese Design (in the editorial of Artcapital in October, 2012)
} 
before its context, can be rescued in the territories of drawing to then reach the project of Design, translating this ambivalence in the shape of the object.

For the most part, in what concerns Design's creative activity, there seems to be a propensity for the intent to deviate, regarding the symbolic. Whereas in the contemporary artistic process the symbolic is a symptom of Art, Design wanders through multiple 'aesthetics', tendentiously global and, as such, away from their identifying relationship with a certain time and place.

\section{References}

BARTOLO J. (2012). 'Manifesto Para O Design Português', in Artecapital. <http://www.artecapital.net/estado-daarte-28-coletivo-manifesto-para-o-design-portugues> [Consulta: 20 de Abril de 2016].

BAUDRILlard, J. (2004). O Sistema dos Objectos. São Paulo: Prespectiva Ed. (1 $1^{\text {a }}$ ed. Le système des objets, Gallimard, 1968)

BUTLER, J. (2002). Cuerpos que importan: sobre los limites materiales y discursivos del "sexo". Buenos Aires: Ediciones Paidos Iberica, S.A. ( $1^{\text {a }}$ ed. Bodies that Mater. On the Discursive Limits of "sex". Routledge, 1993)

CALEJO, M. (2013) 'Drawing as cartographer of everyday life spaces', in DUT (Drawing in the University Today International Meeting on Drawing, Image and Research). Porto: Faculdade de Belas Artes da Universidade do Porto

DERRIDA, J. (2012). A Voz e o Fenómeno. Introdução ao Problema do Signo na fenomenologia de Husserl. Lisboa: Edições 70 ( $1^{\mathrm{a}}$ ed. La Voix et le Phenomene. Presses Universitaires de France, 1967)

DERRIDA J. (2003). Marx no es un Don Nadie, in Peretti, C. (ed.), Espectografias (desde Marx y Derrida). Madrid: Edición Cristina de Peretti ( $1^{\mathrm{a}}$ ed 1997)

FOUCAULT, M. (2012). A Ordem do Discurso aula inaugural no College de France, pronunciada em 2 de dezembro de 1970. São Paulo: Edições Loyola (1 ${ }^{\mathrm{a}}$ ed. Lórde du discurs. Leçon inaugurale au Collége de France pronounce le 2 décembre 1970, Gallimard, 1971)

FOUCAUlT, M. (1967). De Outros Espaços. Conferência proferida por Michel Foucault no Cercle d'Études Architecturales, em 14 de Março de $1967<\mathrm{http} / /$ www.virose.pt/vector/periferia/foucault_pt.html> , [Consulta: 20 Abril 2016]

LARANJO F. (2016). 'Simplismo' in Jornal P3, 19/04/2016. <http://p3.publico.pt/cultura/design/20226/simplismo> [Consulta: 29 de Abril de 2016].

PHELAN, P. (2001). 'A ontologia da performance: representação sem reprodução', Revista de Comunicação e Linguagens, No 24, Lisboa: Edições Cosmos

RICOEUR, P. (1978). Archives, Documents Traces. in The Archive. Edited by Charles Merewether Documents of Art Contemporary, 2006. (p. 66-69) 